\title{
OCORRÊNCIA DE ACIDENTES CAUSADOS POR FERROADAS DE VESPAS NA CIDADE DE PONTA GROSSA - PARANÁ
}

\author{
OCCURRENCE OF ACCIDENTS CAUSED BY WASP STINGS IN \\ PONTA GROSSA - PARANÁ
}

\begin{abstract}
Marcia Regina Paes de Oliveira ${ }^{*}$, Péricles Martim Reche², Leila Silveira Bittencourt'
'Universidade Estadual de Ponta Grossa, Departamento de Biologia Estrutural, Molecular e Genética, Ponta Grossa, Paraná, Brasil. ${ }^{2}$ Universidade Estadual de Ponta Grossa, Departamento de Enfermagem,

Ponta Grossa, Paraná, Brasil

*Autor para contato: Marcia Regina Paes de Oliveira, Departamento de Biologia Estrutural, Molecular e Genética. Av. General Carlos Cavalcanti, 4748 - Ponta Grossa - PR. CEP 84030-900. Telefone institucional Laboratório de Técnicas Histológicas: (42) 32203130 e-mail: marciarpaeso@gmail.com
\end{abstract}

\section{RESUMO}

A vespa Polybia paulista é comum no Brasil, especialmente no estado de São Paulo, podendo ser encontrada nos estados de Goiás, Mato Grosso, Paraná e Minas Gerais. Constrói seus ninhos em áreas urbanizadas, o que resulta numa maior probabilidade de ocorrer acidentes envolvendo essas espécies de artrópodes. O presente trabalho teve como objetivo realizar a coleta de dados sobre a incidência de acidentes causados por ferroadas de vespas, especificamente no município de Ponta Grossa, no estado do Paraná, conhecer os principais sintomas apresentados nos episódios de ferroadas e a porcentagem de pessoas que desenvolveram hipersensibilidade quando expostas ao veneno. Para isso, foi realizado um inquérito epidemiológico, por meio da aplicação de questionário em onze vilas da cidade, situadas próximas às áreas verdes. Os dados obtidos foram tabulados no Microsoft Office Excel e analisados com a utilização do programa Epilnfo, mediante análises exploratórias e estratificadas. Os resultados mostraram que dos 915 moradores entrevistados, $37,81 \%$ já haviam sido ferroados por vespas, dos quais somente $4,60 \%$ desenvolveram hipersensibilidade, mesmo com a presença de somente $22(2,40 \%)$ ninhos da vespa Polybia paulista nas residências visitadas. Os locais do corpo mais atingidos por ferroadas foram as mãos $(17,27 \%)$ e os braços $(10,20 \%)$. De acordo com os resultados, pôde-se concluir que, nos bairros selecionados para o estudo, apesar da pequena quantidade de ninhos de vespa encontrados nas residências, detectou-se a ocorrência de número significativo de ferroadas, sendo os homens, os mais suscetíveis.

Palavras-chave: vespa, ferroada, ninho, hipersensibilidade.

\section{ABSTRACT}

The wasp Polybia paulista is common in Brazil, especially in São Paulo, and can be also found in the states of Goias, Mato Grosso, Parana and Minas Gerais. These insects build their nests in urban areas, which results in higher probability of accidents with such arthropod species. This study aimed to collect data about the incidence of accidents, the knowledge of the main symptoms reported in sting episodes and the rate of people who presented hypersensitivity after wasp sting in Ponta Grossa-PR. To reach this objective, an epidemiological survey was carried out through 
a questionnaire applied in eleven neighborhoods of the city, located near green areas. The data obtained were tabulated in Microsoft Office Excel and analyzed by using Epilnfo, through exploratory and stratified analyses. The results showed that out of the 915 residents interviewed $37.81 \%$ were stung by wasps, among them, only $4.60 \%$ developed hypersensitivity, even with the presence of only twenty-two (2.40\%) Polybia paulista wasp nests in the homes visited. The parts of the body most affected by stings were the hands (17.27\%) and arms (10.60\%). The results led to the conclusion that in the neighborhoods selected for the study, despite the small number of households with wasp nests, the occurrence of a significant number of stings was detected, and that the male population is the most susceptible to this kind of incident.

Keywords: wasp, sting, nest, hypersensitivity.

\section{INTRODUÇÃO}

A anafilaxia, uma reação alérgica aguda grave, de início súbito, evolução rápida e potencialmente fatal (BERND et al., 2006) pode ser desencadeada por diversos agentes etiológicos, dentre os mais conhecidos estão os medicamentos, os alimentos e o veneno de insetos da ordem Hymenoptera (KEMP; LOCKEY, 2002). Brown et al. (2001) mostraram que, dos principais agentes desencadeadores de reações anafiláticas, os fármacos são responsáveis por $28 \%$ dos casos, seguidos pelas ferroadas de insetos que representam $17,5 \%$.

A ordem Hymenoptera que inclui abelhas, vespas e formigas é conhecida há muito tempo como um fator de risco ambiental em potencial (BETTEN et al., 2006), uma vez que uma única ferroada desses insetos pode resultar em complicações com risco para a vida (BHATTA et al., 2005). Acidentes graves e mortes por ferroada de abelhas africanizadas são registrados com maior frequência, não pela diferença de composição do veneno, mas pela maior agressividade dessa espécie, em ataques maciços (ESTATÍSTICA ANUAL DE CASOS DE INTOXICAÇÃO E ENVENENAMENTO, 1999).

A vespa Polybia paulista, espécie comum no Brasil, principalmente nos estados de São Paulo, Goiás, Mato Grosso, Paraná e Minas Gerais (MACHADO, 1984) apresenta glândulas especializadas na produção de veneno e aparelho de ferroar, para utilizar tanto na caça de presas quanto em sua própria defesa (STEEN et al., 2005). O veneno de vespa é uma mistura complexa de proteínas e aminas biogênicas, com potencial farmacológico e bioquímico semelhante àqueles encontrados em serpentes e escorpiões (HABERMANN, 1972). Os principais alérgenos encontrados nesses venenos são as enzimas fosfolipase, hialuronidase e serino proteases, além de proteínas não enzimáticas, como por exemplo, o antígeno 5 (SANTOS et al., 2007).

A prevalência, na Europa, de pessoas alérgicas ao veneno de Hymenoptera é de 20\%, considerando as reações locais e sistêmicas (RODRIGUES; RIBEIRO, 2013). Bilò et al. (2005) estimaram a incidência de casos fatais, na Europa, entre 0,009 e 0,45 por milhão de habitantes/ano, resultando em cerca de 100 mortes ao ano. No Brasil, dados sobre a incidência de acidentes com vespas são escassos, embora se saiba que casos fatais têm sido documentados desde a década de 60 (SISTEMA NACIONAL DE VIGILÂNCIA EM SAÚDE, 2013).

O desmatamento de florestas vem causando a fragmentação da mata, antes contínua, levando ao aparecimento de ilhas de matas, isoladas umas das outras, por áreas cobertas de paisagem ou 
por algum outro tipo de plantação. Além da perda de espécies, provocada pela destruição da mata, podem ocorrer modificações nos fragmentos, com o passar do tempo, relacionados à diversidade e à composição de sua fauna e flora, devido ao rompimento de antigas interações entre espécies e ao estabelecimento de novas, bem como de modificações nos processos biológicos e nas características do microclima e solo (LOVEJOY, 1980).

Diante desse cenário, diversas espécies deixam seu habitat natural em busca de refúgio, abrigo e alimento, em áreas urbanas, incluindo algumas espécies de vespas que tendem a formar suas colônias em qualquer local, desde que atenda às suas necessidades básicas de sobrevivência (RIBEIRO, 2010).

A construção de ninhos de vespas sociais, associada à edificação humana confere a eles uma maior chance de sucesso, uma vez que no ambiente urbano ocorre uma grande redução da pressão de predação, bem como uma maior oferta de ambientes para a construção de ninhos protegidos das intempéries climáticas (FOWLER, 1983; RAMOS; DINIZ, 1993).

Durante o desenvolvimento, a colônia precisa de água para o controle da temperatura; polpa vegetal para a construção e o reparo do ninho; carboidratos para a alimentação de larvas e adultos, além de proteína animal para as larvas (PREZOTO et al., 1994; RESENDE et al., 2001). Assim, as áreas de vegetação contribuem para a ocorrência de insetos sociais, o que as tornam locais de grande importância, pois permitem condições favoráveis à construção de ninhos de vespas e possibilitam o aumento da ocorrência de acidentes com tais espécies de animais peçonhentos.

Sabendo-se da escassez de dados epidemiológicos sobre espécies de vespas brasileiras, o presente trabalho tem a finalidade de realizar um levantamento sobre: a incidência de acidentes por ferroadas de vespas; o conhecimento dos principais sintomas apresentados nos episódios de ferroadas e a porcentagem de pessoas que desenvolvem hipersensibilidade aos venenos, focalizando bairros situados próximos às áreas verdes da cidade de Ponta Grossa. O conhecimento dessas variáveis visa buscar estratégias para a prevenção de episódios de ferroadas, os quais possam evoluir para reações graves de anafilaxia na população.

\section{MATERIAL E MÉTODOS}

Ponta Grossa é um município brasileiro do estado do Paraná, distante $103 \mathrm{Km}$ da capital Curitiba, com uma população de 351.736 habitantes, segundo o censo de 2019 (IBGE, 2019). Essa cidade, assim como muitas no Brasil, não contou com o devido planejamento e nem conta com a adequada manutenção, no que diz respeito à arborização urbana (QUADROS, 2009).

Para a escolha das regiões analisadas foram considerados os seguintes parâmetros: proximidade da mata e abundância de água, fatores essenciais para a construção dos ninhos de vespa. Desta forma foram selecionados no bairro de Uvaranas o Núcleo Rio Verde, a vila Dal Col e o Núcleo David Federmann; no bairro de Oficinas o Jardim Itália e o Jardim Europa; no bairro Estrela, as vilas Placidina e América I, no bairro Nova Rússia, a vila Clock e vila Santo Antonio, no bairro Contorno a vila Verona e no bairro Neves, a vila Dos Neves (Figura 1).

Todas as habitações, localizadas nos referidos bairros, foram investigadas, exceto prédios comerciais, conjuntos e/ou prédios residenciais, moradias vazias, em reforma, à venda, para locação ou em que, por mais de duas vezes, os moradores não estavam presentes. 
Figura 1 - Mapa dos bairros da cidade de Ponta Grossa.

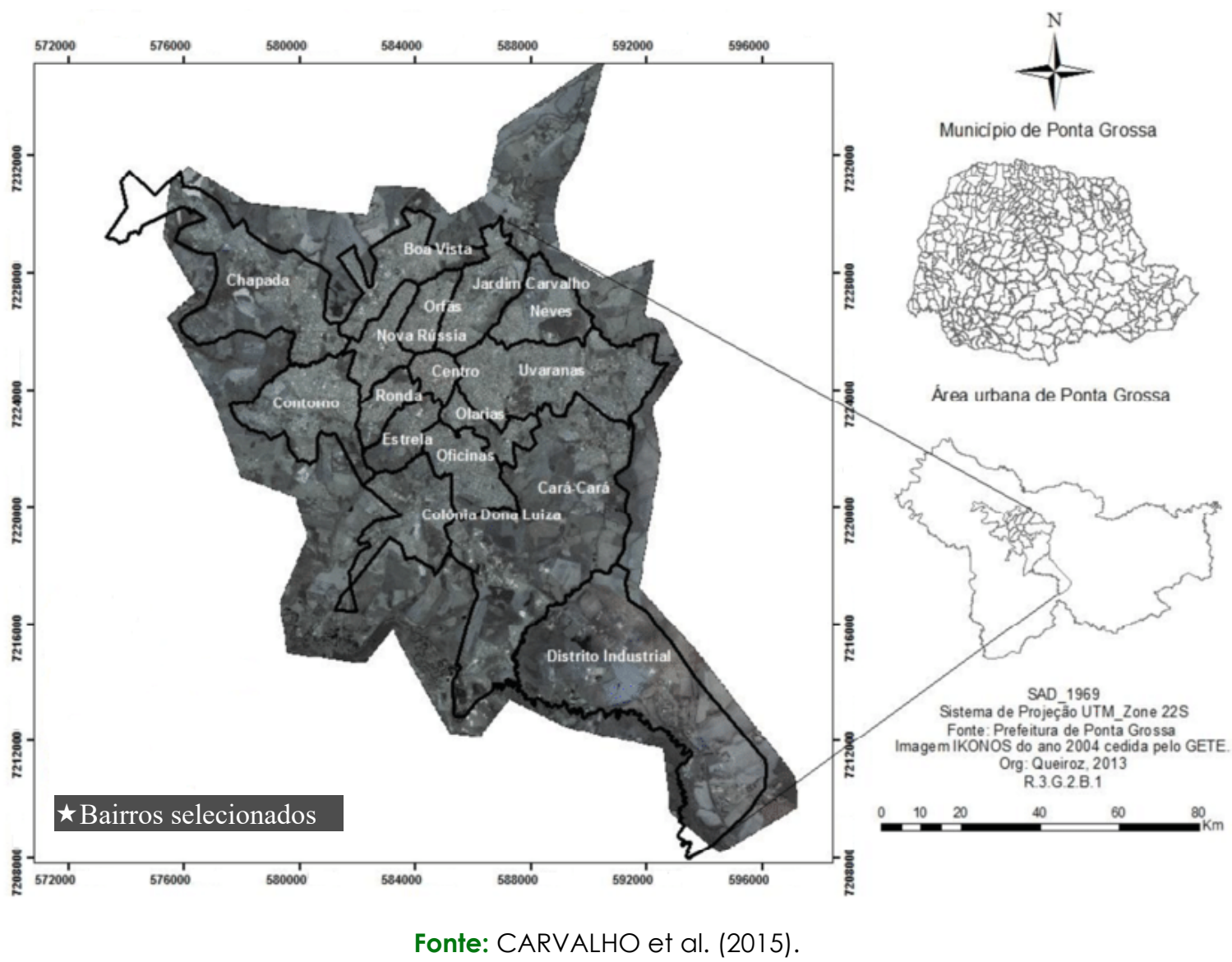

A população de estudo foi constituída por moradores (população humana), ninhos da vespa social Polybia paulista e porcentagem de ferroadas ocasionadas por Hymenoptera sociais, nos bairros selecionados para a realização do estudo, na cidade de Ponta Grossa.

Um questionário foi aplicado, a partir do qual se adotou a amostragem por conveniência, em que a amostra é formada obedecendo a algum tipo de conveniência, seja de quem a forma, seja de quem irá participar dela ou de ambos os casos; por facilitar o acesso aos locais de trabalho de campo, pelo seu baixo custo e pela rapidez na coleta de dados. No caso deste estudo, os entrevistados tiveram a opção de aceitar, ou não, participar da pesquisa. As visitas foram realizadas nos mais diferentes horários, abrangendo os dias de segunda-feira a domingo, buscando sempre encontrar o maior número de residências com moradores.

A variável-resposta foi definida como tipo de habitação, a qual foi categorizada em moradias com e sem acidentes provocados pelas vespas. Como variáveis independentes foram coletados: o local e a área geográfica de localização da residência, o sexo e a renda familiar total.

A respeito dos ninhos e ferroadas foram coletados os seguintes dados: existência de ninho de vespa na residência e se esse era de Polybia paulista, se o morador já haviasido ferroado por vespa e se lembrava da época em que isso ocorreu, descrição dos sinais observados após a ferroada, conhecimento sobre alguém que já foi ferroado por vespa, existência de animais domésticos e plantas na moradia, se o morador trabalha fora de casa e o tipo de habitação visitada. 
Posteriormente, todos os dados obtidos foram tabulados no Microsoft Office Excel e analisados mediante a utilização do programa Epilnfo 7.2, 2018.

A análise dos dados foi realizada em duas fases: Na primeira delas, nomeada análise exploratória dos dados, foram produzidos os gráficos e as tabelas para variáveis discretas; os gráficos, as medidas de tendência central e de dispersão, para variáveis contínuas. Na segunda fase foram realizadas algumas análises estratificadas, a fim de remover o efeito de variáveis de confundimento.

Este projeto foi aprovado pelo Comitê de Ética em Pesquisa da Universidade Estadual de Ponta Grossa (parecer n. 1.785.108 de 21/10/2016).

\section{RESULTADOS E DISCUSSÃO}

No total foram visitadas 1.214 habitações, 915 moradores delas concordaram em participar do estudo, o que representa 75,37\% do total de moradias visitadas, 109 pessoas recusaram-se perfazendo uma porcentagem de $8,98 \%$ do total de habitações. As moradias restantes $(15,65 \%)$ estavam em reforma, à venda, para locação, vazias ou os entrevistadores não foram recebidos pelos moradores. Das habitações analisadas, apenas 22 (2,40\%) apresentaram ninhos de Polybia paulista presos aos seus beirais.

Dos 915 entrevistados, 346 (37,81\%) relataram já terem sido ferroados por vespas e 569 (62,19\%) nunca foram. Ao relacionar o gênero com o número de acidentes ocasionados por vespas, notou-se que a frequência de ferroadas foi maior entre os homens, os quais representaram 44,35\% dos casos. Já as mulheres representaram 33,51\% dos casos registrados (Tabela I). Esse resultado corrobora o estudo realizado por Dorneles (2009), acerca da incidência de acidentes envolvendo várias espécies de animais peçonhentos, o qual evidenciou que pessoas do sexo masculino são mais atingidas, se comparadas às do sexo feminino. Uma possível explicação para esse achado pode estar associada ao fato de que, na maioria das vezes, é o homem quem realiza a retirada dos ninhos, ficando mais suscetível ao ataque dos animais peçonhentos.

Tabela I - Distribuição da ocorrência de ferroadas de Hymenoptera, segundo o gênero, masculino ou feminino, em bairros próximos às áreas verdes, na cidade de Ponta Grossa - PR.

\begin{tabular}{|c|c|c|c|c|c|}
\hline \multirow{3}{*}{ Gênero } & \multicolumn{4}{|c|}{ Ferroado } & \multirow{3}{*}{ Total } \\
\hline & \multicolumn{2}{|c|}{$\operatorname{Sim}$} & \multicolumn{2}{|c|}{ Não } & \\
\hline & n..$^{\circ}$ & $\%$ & n..$^{\circ}$ & $\%$ & \\
\hline Masculino & 161 & 44,35 & 202 & 55,65 & 363 \\
\hline Feminino & 185 & 33,51 & 367 & 66,49 & 552 \\
\hline Total & 346 & 37,81 & 569 & 62,19 & 915 \\
\hline
\end{tabular}

A mão foi o local do corpo em que a ferroada foi mais frequente, representando 158 casos (17,27\%), seguido pelo braço com 97 ocorrências relatadas (10,60\%) e o pescoço com 50 casos apresentados (5,46\%), conforme evidencia a Tabela II. 
Tabela II - Locais do corpo mais comumente atacados, nos episódios de ferroadas por vespas, relatados por residentes de bairros próximos às áreas verdes, na cidade de Ponta Grossa - PR.

\begin{tabular}{l|l|l}
\hline LOCAL DA FERROADA & NÚMERO & PORCENTAGEM \% \\
\hline Mão & 158 & 17,27 \\
\hline Braço & 97 & 10,60 \\
\hline Pescoço & 50 & 5,46 \\
\hline Corpo & 21 & 2,30 \\
\hline Rosto & 17 & 1,86 \\
\hline Costas & 3 & 0,33 \\
\hline
\end{tabular}

Nesse aspecto, os dados obtidos no presente estudo, assemelham-se ao erucismo, descrito por Cruz e Barbola (2016), os quais observaram que a mão havia sido o local do corpo mais atingido nos acidentes envolvendo lagartas, na cidade de Ponta Grossa.

O motivo de as mãos apresentarem maior frequência aos ataques pode ser explicado pela maior exposição desta parte do corpo, uma vez que algumas vítimas de ferroadas das vespas, relatarem que os acidentes ocorreram durante a poda de árvores, na aproximação ao ninho e tentativa de retirada desse.

Da mesma forma, o estudo realizado por Batista (2015), na cidade paraibana de Campina Grande, revelou que, as regiões anatômicas mais frequentemente atingidas em acidentes com vespas e abelhas foram os membros superiores, com destaque para a região da cabeça.

Com relação à época do ano em que os episódios de ferroadas ocorreram, observou-se que 226 foram no verão (24,70\%), 60 na primavera (6,56\%) e 20 no inverno (2,19\%). A maioria dos entrevistados, 609 (66,55\%), vítimas de ferroadas de vespa, não souberam informar a época em que o acidente ocorreu (Figura 2).

Figura 2 - Número de ferroadas de vespa, segundo os relatos de moradores residentes em bairros próximos às áreas verdes, na cidade de Ponta Grossa - PR, considerando a época do ano.

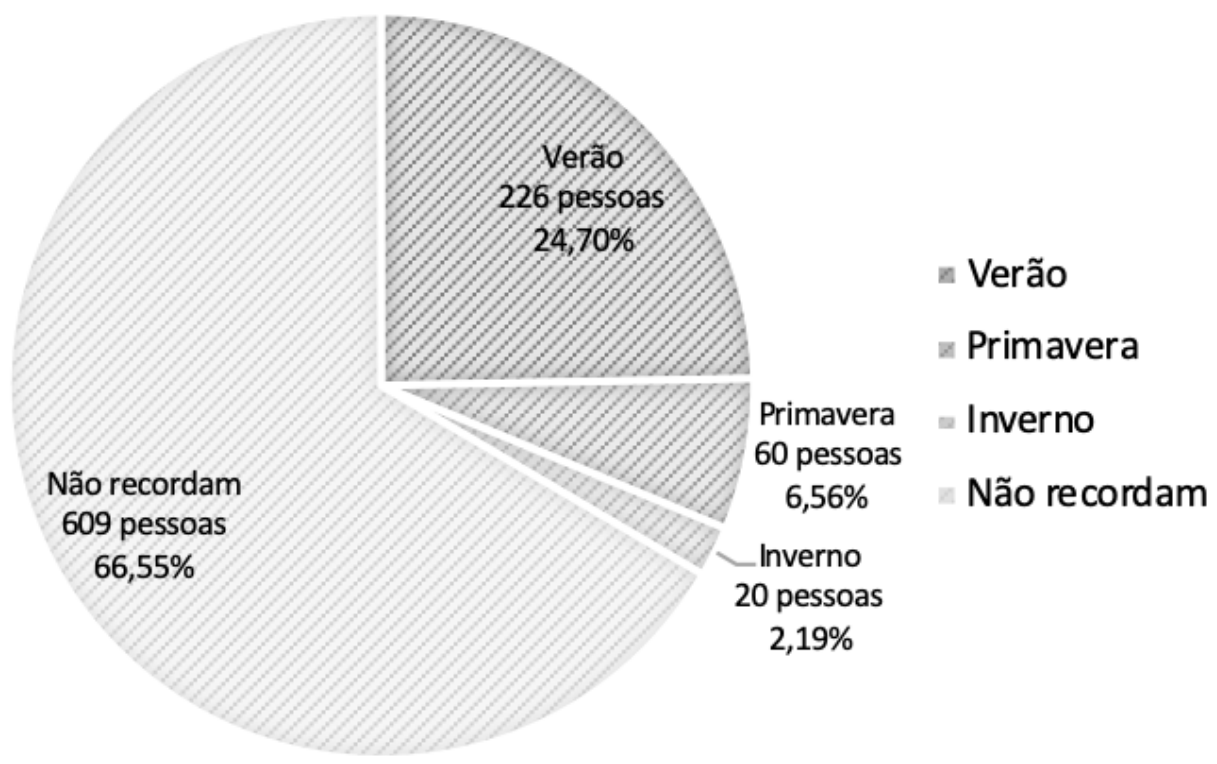


A ocorrência de maior número de casos de ferroadas por Hymenoptera no verão, assemelha-se aos achados de Dorneles (2009), o qual observou uma maior frequência de acidentes, causados por animais peçonhentos, nos meses mais quentes do ano.

O estudo do perfil epidemiológico de acidentes, causados por abelhas e vespas, na cidade paraibana de Campina Grande, mostrou que a maior incidência também ocorreu no período da primavera e verão (Batista, 2015).

A explicação para esse fenômeno está no fato de que, essas estações, com maiores temperaturas e disponibilidade de alimentos, favorecem a reprodução de indivíduos nas colônias, assim como o número crescente de enxames, favorecendo o contato desses animais com o ser humano (OLIVEIRA, 2007). Da mesma forma, Bischof (1996) observou que a alta incidência de ferroadas pela vespa Yellow jacket acontece no final do verão e início do outono, época em que esses insetos estão se preparando para a estação mais fria do ano.

Em contraste, Morais et al., (2009) observaram prevalência de casos de acidentes por animais peçonhentos, incluindo aranhas e escorpiões, no outono, seguido do verão.

Canevazzi et al. (2008) encontraram uma correlação positiva entre temperatura e atividade de voo para a vespa da espécie Polybia paulista. Esse aumento relativo das atividades externas em função da temperatura pode ser explicado pela maior entrada de água no ninho. É importante ressaltar que, não somente os fatores abióticos do meio influenciam a variação das atividades de forrageio das vespas sociais, como também as características intrínsecas do ninho e disponibilidade de recursos.

Dentre os principais sinais observados após a ferroada, 125 pessoas (13,70\%) relataram sentir somente dor no local; outras 47 (5,15\%) observaram apenas inchaço; enquanto 52 pessoas (5,70\%) apresentaram dor e inchaço e 45 (4,95\%) relataram vermelhidão (Tabela III).

Tabela III - Principais sinais relatados pelas vítimas de ferroadas de vespa, residentes em bairros próximos às áreas verdes, na cidade de Ponta Grossa - PR.

\begin{tabular}{l|l|l}
\hline SINAIS OBSERVADOS & NÚMERO & PORCENTAGEM \% \\
\hline Dor & 125 & 13,70 \\
\hline Dor e inchaço & 52 & 5,70 \\
\hline Inchaço & 47 & 5,15 \\
\hline Vermelhidão & 45 & 4,95 \\
\hline Dor e vermelhidão & 39 & 4,10 \\
\hline Inchaço e vermelhidão & 24 & 2,65 \\
\hline Hipersensibilidade & 16 & 1,75 \\
\hline
\end{tabular}

A dor e o inchaço foram os sintomas mais comuns nos casos de envenenamento por Hymenoptera, causado por componentes vasoativos do veneno (FITZGERALD e FLOOD, 2006). Normalmente ocorreu em indivíduos não alérgicos, o que corresponde à maioria da população (BOUSQUET et al., 1984; PAULA et al., 2006).

A mais severa das reações observadas, em episódios de ferroadas por Hymenoptera, foi a sistêmica, conhecida como resposta anafilática, caracterizada por vários graus de urticária, angioedema, náusea, vômito, hipotensão e dispneia resultantes da hipersensibilidade imediata (FITZGERALD e FLOOD, 2006). 
Das 346 pessoas que foram ferroadas por vespas, somente 16 (4,60\%) experimentaram reações de hipersensibilidade. Esse resultado assemelha-se ao encontrado na literatura específica, a qual relata que as reações sistêmicas de hipersensibilidade a ferroadas de Hymenoptera ocorrem entre 0,8\% e 5\% da população mundial (CHARPIN et al., 1992).

Apesar da baixa porcentagem de ocorrência de reações anafiláticas, encontradas no presente estudo, o alerta à população sobre a importância do acompanhamento dos sintomas após acidentes, com Hymenoptera, pode ser uma medida profilática efetiva para a redução e/ou extinção de casos de anafilaxia. Vale ressaltar que, casos de anafilaxia podem ocorrer como resultado de uma única ferroada ou após acidentes com múltiplas ferroadas, sendo essas últimas resultantes do manejo inadequado durante podas de árvores e retirada de ninhos das residências.

A intensidade das lesões teciduais, causada pelo veneno de vespa, pode ser parcialmente explicada pela suscetibilidade dos tecidos da vítima ao veneno, e pelo tipo de toxina presente nele (CHAO; LEE, 1999). Para os casos de lesões mais graves, o reconhecimento dos sintomas apresentados, nesses episódios de ferroadas, é de fundamental importância para que o tratamento seja iniciado o mais breve possível (THIRUVENTHIRAN et al., 1999) e para que seja realizada a conduta adequada perante às vítimas, uma vez que não há antiveneno para Hymenoptera (BETTEN et al., 2006).

\section{CONCLUSÃO}

O presente estudo mostrou que, pouco mais de 1/3 da população analisada, foi vítima de ferroadas por vespas, na cidade de Ponta Grossa. A maior incidência de ferroadas de Hymenoptera foi observada na população masculina, sendo que, a maioria das vítimas apresentou sintomas leves, normalmente observados em pessoas não alérgicas, contrastando com uma pequena porcentagem de pessoas que experimentou reações de hipersensibilidade. O local mais atingido, no corpo, foi a mão e os episódios de ferroadas ocorreram, com maior frequência, no verão, sugerindo que um dos fatores que contribuiu à ocorrência de tais acidentes possa ter sido o manejo inadequado desses animais, pelo ser humano. Assim, torna-se necessário informar à população sobre a biologia e o manejo de vespas sociais, a fim de reduzir a ocorrência de acidentes.

\section{REFERÊNCIAS}

Acidentes por Animais peçonhentos. Estatística Anual de Casos de Intoxicação e Envenenamento, 1999.

BATISTA, C.W.A. Análise dos casos de acidentes causados por abelhas e vespas em um centro de controle de intoxicação em um município paraibano - Campina Grande, Paraíba. Trabalho de Conclusão de Curso. Universidade Estadual da Paraíba. Campina Grande - Paraíba, 2015.

BERND, L.A.; SOLÉ D, PASTORINO, A.C.; PRADO, E.; CASTRO, F.F.; RIZZO, M.C. Anafilaxia: guia prático para o manejo. Rev. Bras. Alerg Imunopatol., v. 29, p. 283-291, 2006.

BETTEN, D.P.; RICHARDSON, W. H.; TONG, T. C.; CLARK, R. F. Massive HoneyBee EnvenomationInduced Rhabdomyolysis in an Adolescent. Pediatrics. v. 117, n. 1, p. 231-235, 2006.

BHATTA, N.; SINGH, R.; SHARMA, S.; SINNHA, A.; RAJA, S. Acute renal failure following multiple wasp stings. Pediatric Nephrology, v. 20, n. 12, p. 2005. 
BILÒ, B.M. Diagnosis of Hymenoptera venom allergy. Allergy, v. 60 n. 11, p. 1339-1349, 2005. BISCHOF, R.O. Seasonal incidence of insect stings: "Autumn yellow jacket delirium". Journal of family practice. v. 43, n. 3, p. 271-273, 1996.

BOUSQUET, J.; HUCHARD, G., MICHEL, F.B. Toxic reactions induced by Hymenoptera venom. Ann. Allergy, v. 52, p. 371-374, 1984.

BROWN, A.; MCKINNON, D.; CHUCK. Emergency department anaphylaxis: A review of 142 patients in a single year. J. Allergy Clin Immunol, v. 108, p. 861-866, 2001.

CANEVAZZI, N.C.S.; NOLL, F.B. The influence of temperature on the foraging activity of the neotropical social wasp Polybiapaulista (hymenopetera: vespidae, epiponini), 2008.

CARVALHO, S. M.; QUEIROZ, D.; EURICH, Z. R. S. Espaços livres em Ponta Grossa - Paraná: Mapeamento e quantificação. Bol. Geogr., v. 33, n. especial, p. 1-12, 2015.

CHAO S. C.; LEE Y. Y. Acute rhabdomyolysis and intravascular hemolysis following extensive wasp stings. International Journal of Dermatology, v. 38, n. 2, p. 135, 1999.

CHARPIN, D., BIRNBAUM, J.; LANTEAUME, A., VAVBOET, D. Prevalence of allergy to Hymenoptera stings in diferent samples of the general population. J. Allergy Clin. Immunol., v. 90, p. 331-334, 1992.

DA CRUZ, A.C.P.; BARBOLA, I.F. Acidentes provocados por lagartas urticantes em Ponta GrossaParaná. Publicatio Ciências Biológicas, v. 22, n. 1, p. 309-39, 2016.

DE MORAIS, J.M.; PEREITA, M. L.; JUNIOR, S.I.S. Sazonalidade dos Acidentes com Animais Peçonhentos nos Municípios Adscritos à GRS de Alfenas no Triênio 2007-2009, 2009.

DORNELES, A.L. Frequência de acidentes por animais peçonhentos ocorridos no Rio Grande do Sul, 2001-2006. UFRGS - Universidade Federal do Rio Grande do Sul. Porto Alegre, 2009.

FITZGERALD, K.T.; FLOOD, A.A. Hymenoptera stings. Clinical Techniques in small animal practice, v. 21, p. 194-204, 2006.

FOWLER, H.G. Human effects on nest survivorship of urban synanthropic wasps. Urban Ecol., v. 7, p. 137-143, 1983.

HABERMANN, E. Bee and wasp venoms: the biochemistry and pharmacology of their peptides and enzymes are reviewed. Science, v. 177, p. 314-322, 1972.

IBGE - INSTITUTO BRASILEIRO DE GEOGRAFIA E ESTATÍSTICA. Estimativa da população da cidade de Ponta Grossa em 2019. Disponível em: <http://cod.ibge.gov.br/6N1>.

KEMP, S.F.; LOCKEY, R.F. Anaphylaxis: a review of causes and mechanisms. J Allergy Clin. Immunol., V. 110, p. 341-348, 2002.

LOVEJOY, T.E. Discontinuous wilderness: minimum areas for conservation. Parks, v. 5, n. 2, p. 13-15, 1980.

MACHADO, V. L. L., Análise populacional de colônias de Polybia (Myrapetra) paulista (Ihering, 1896) (Hymenoptera, vespidae). Revista brasileira de Zoologia, v. 2, n. 4, p. 187-201, 1984.

OLIVEIRA, A.M. Distribuição espacial e temporal de abelhas melíferas africanizadas e vespídeos (Hymenoptera) na cidade de São Paulo. Tese de Doutorado. Universidade de São Paulo, 2007. 
PAULA, L.; DE SANTOS, W.F.; MALHEIRO, A., CARLOS, D.; FACCIOLI, L.H. Differential modulation of cell recruitment and acute edema in a modelo of Polybia paulista venom-induced inflammation. International Immunopharmacology, v. 6, p. 182-189, 2006.

PREZOTO, F.F.; GIANNOTTI, E.; MACHADO, V.L.L. Atividade forrageadora e material coletado pela vespa social Polistes simillimus Zikán (1951). (Hymenoptera, Vespidae). Insecta, v. 3, n. 1 p. 11 -19, 1994.

QUADROS, G.P. (DES)CONSTRUÇÃO DO ESPAÇO VERDE EM PONTA GROSSA - PARANÁ. Dissertação de Mestrado em gestão do território - Universidade Estadual de Ponta Grossa. 2009.

RAMOS, F.A.; DINIZ, I.R. Seasonal cycles, survivorship and grown of colonies of Polistes versicolor (Hymenoptera - Vespidae) in the urban area of Brasilia - Brazil. The Entomologist, v. 112, n. 3, p. 191199, 1993.

RESENDE, J.J.; SANTOS, G.M.; BICHARA FILHO, C.C.; GIMENES, M. Atividade diária de busca de recursos pela vespa social Polybia occidentalis occidentalis (Oliver, 1791) (Hymenoptera, Vespidae). Ver. Bras. Zoociências, v. 3, n. 1, p. 105-115, 2001.

RIBEIRO, D.G. Diversidade de vespas (Hymenoptera, Vespidae) no período urbano de Cascavel - Paraná. Trabalho de Conclusão de Curso. Faculdade Assis Gurgacz (FAG). Cascavel - Paraná. 2010.

RODRIGUES, A.; RIBEIRO, J. Alergia a veneno de himenópteros. Revista de Saúde Amato Lusitano, n. 32, p. 19-24, 2013.

SANTOS, L.D.; SANTOS, K.S.; DE SOUZA, B.M.; ARCURI, H.A.; CUNHA-NETO, E.; CASTRO, F.M.; KALIL, J.E.; PALMA, M.S. Purication sequencing and estructural characterization of the phospholipase A 1 from the venom of the Polybiapaulista (Hymenoptera, Vespidae). Toxicon., v. 50, n. 7, p. 923-937, 2007.

SISTEMA NACIONAL DE VIGILÂNCIA EM SAÚDE; Relatório de situação, Paraná; Ministério da Saúde. Disponível em: <http://portal.saude.gov.br/portal/arquivos/pdf/6_parana_final.pdf>. Acesso em: 25/09/2019.

STEEN, C.J.; JANNIGER, C.K.; SCHUTZER, S.E.; SCHWARTZ, R.A. Insect sting reactions to bees, wasps and ants. Int. J. Dermatol., v. 44, p. 91-94, 2005.

THIRUVENTHIRAN, T.; GOH, B.L.; LEONG, C.L.; CHEAH, P.L.; LOOI, L.M.; TAN, S.Y. Acute renal failure following multiple wasp stings. Nephrology Dialysis Transplantation, v. 14, p. 214-217, 1999. 